\title{
Uma contribuição ao desenvolvimento da Economia Política Internacional do Brasil
}

\author{
Joaquim Carlos Racy* \\ Álvaro Alves de Moura Júnior ${ }^{* *}$ \\ Bruno Falsarella ${ }^{* * *}$ \\ Laura Gonçalves ${ }^{* * * *}$
}

\section{Abstract}

This article aims to list some critical aspects of the International Political Economy in its current configuration, i.e., as a field of reflection and interpretation of the economic and political reality, as wellas to briefly point out some fundamental elements of the economic thought to comprehend the relations between economics and politics on the international level put forth by classical authors. This is the case of Smith, Ricardo, List and Keynes who had a strong involvement with such issues. Therefore, the study is largely exploratory and searches only to simulate a debate to promote the construction of a cornerstone for the development of this area of thought and its applicability in Brazil even recovering its interdisciplinary character. For this reason, the Marxist analysis of the international reality is excluded from this article. 


\section{1_Introdução}

A Economia Política Internacional vem se constituindo nos últimos anos como uma área de particular interesse tanto para economistas quanto para cientistas políticos.

Por seu caráter recente e interdisciplinar, os estudos com esse recorte ainda não compõem uma metodologia que lhes garanta qualquer autonomia, mas identificam claramente a natureza das relações internacionais contemporâneas, devendo assumir função primordial na explicação de como se articulam as duas instâncias da realidade a que se referem.

O fato de ainda não constituírem um campo autônomo de conhecimento também parece se dever à dificuldade que os economistas encontram em dialogar com outras áreas das ciências sociais e uma recusa em reconhecer o que alguns dos autores clássicos da economia lograram no estudo dos problemas internacionais.

Em função disso, o artigo se desenvolve tendo como início uma discussão introdutória sobre o estatuto da Economia Política Internacional. Em seguida são apresentados os posicionamentos de autores clássicos da economia (Smith, Ricardo, List e Keynes) de forma a ressaltar suas manifestações sobre essa questão e a importância a ela atribuídas, assim como seus possíveis encaminhamentos.

\section{2_A Economia Política Internacional: um método de análise ou a expressão de ideologias?}

A Economia Política Internacional enquanto um esforço no sentido de desenvolver estudos sistematizados sobre os problemas internacionais tem sua origem e denominação nos anos iniciais da década de 70 do século passado. Os responsáveis por isso no campo da economia são Charles Kindleberger, em primeiro lugar, seguido de Robert Gilpin e Susan Strange com uma interessante contribuição dos cientistas políticos Joseph Nye e Robert Keohane.
Baseado na crise que resultaria no fim do Sistema Bretton Woods, Kindleberger (1970) observava que a perspectiva de uma realidade internacional pautada por relações entre nações deixadas à própria sorte, colocando-se aí a perspectiva de retomada da predominância das teorias de livre comércio na delimitação das relações entre as nações, empurraria o mundo para uma completa instabilidade, gerando condições muito semelhantes às vividas na Grande Depressão. A estabilidade do "sistema" exigia a figura de um hegêmona.

A essa concepção Keohane e Nye, cientistas políticos especializados em assuntos internacionais, chamariam de "estabilidade hegemônica" e a considerariam, com certo tom crítico, uma expressão da teoria realista, aceita por Gilpin, sobre as relações internacionais.

Em boa medida, identificada com aqueles autores, $\mathrm{Su}$ san Strange, também no início dos anos 70 preocupava-se com a mudança que passava a se observar na realidade internacional e que indicava uma tendência de superação do sistema interestatal que caracterizara até então a ordem internacional, com o surgimento de outros atores que proporcionavam novas formas de articulação política.

Os autores considerados passavam a demonstrar uma preocupação, que até então parecia desprezada, no sentido de tentar trazer para o debate econômico a questão política, ao mesmo passo que para o debate político a questão econômica. Naturalmente, os elementos históricos da realidade não podem ser descolados de sua interpretação e, nessa medida, numa confluência entre Economia, Política e a própria História.

No entanto, a EPI não se constitui ainda como um campo de conhecimento autônomo. Assim como na Teoria de Relações Internacionais - TRI, trata-se de um esforço recente nascido de uma necessidade real de compreensão 
do mundo principalmente após a II Grande Guerra e seus desdobramentos. Na realidade, a EPI é tributária da TRI, mas em função das condições e do período em que se desenvolve, faz com que seja considerada por Gilpin e Strange somente um método de abordagem para os problemas da realidade internacional.

O que dá corpo a este artigo, referindo-se à consideração anterior quanto à natureza da EPI, é o fato de que as diferentes concepções ou interpretações das relações econômicas internacionais se manifestam, por um lado, de maneira ideológica ao mascararem de forma quase que sectária a própria realidade e, por outro, de maneira fragmentada ao separarem absolutamente a política da economia. Tal comportamento cria sérios obstáculos ao desenvolvimento de métodos de procedimentos que venham a conferir um caráter científico e alguma autonomia a esse campo de conhecimento. Nesse sentido, conforme aponta Gilpin em seu livro seminal A Economia Política das Relações Internacionais:

Nos últimos 150 anos, três ideologias dividiram a humanidad e-oliberalismo, o nacionalismo e o marxismo. [...] As três ideologias citadas diferem em um amplo cardápio de perguntas [...] (GILPIN, 2002, p. 43).

E é, segundo o autor, exatamente essa a divisão que marca o estudo da Economia Política Internacional.

Uma primeira crítica que então se pode colocar quanto ao estado da EPI diz respeito à situação em que o diferencial entre as ideologias que lhe dão corpo não se dá em função do cardápio das perguntas efetuadas para a elaboração de interpretações da realidade internacional, mas sim do cardápio de respostas antecipadamente estabelecidas sobre a ordem econômica e política internacional.

Nesse sentido, deve-se assinalar que as concepções dominantes sobre a realidade internacional na perspectiva da
EPI, conforme o próprio Gilpin, estão fundadas nas teorias econômicas clássicas, particularmente no que se refere ao comércio entre as nações. Sendo aquelas depositárias de sua época, acabam por transportar para este campo o debate ideológico que galvaniza o pensamento econômico ainda hoje, definindo as relações entre as nações ou as relações internacionais como determinadas categoricamente por relações entre Estados ou entre agentes de Mercado, excludentemente. Isto é, tudo gira em torno de Estado ou Mercado.

Segundo se supõe aqui é essa categorização que consubstancia o nó que atrasa o desenvolvimento da EPI enquanto campo de conhecimento autônomo na medida em que impede a construção de um método de análise da realidade relativamente isento.

Isso, contudo, não faz da EPI um campo de estudo completamente diferente de outros tais como a própria TRI, que estão irremediavelmente permeados por certa normatividade. Por lidarem com questões relativas a poder e por circunstâncias históricas reais, essas áreas de conhecimento assumem necessariamente um caráter prescritivo.

Todavia, no caso da Teoria das Relações Internacionais, que mereceria maior atenção por parte dos economistas, e cujos esforços se desenvolvem de forma ordenada há mais tempo que na EPI, as delimitações teóricas não se dão da maneira como acontece nesta área.

Sob esse aspecto, embora a característica do pensamento clássico na TRI seja de uma divisão entre "realismo" e "idealismo", o que acaba por caracterizar também a perspectiva de compreensão da realidade internacional da EPI, na TRI clássica não se observa a excludência notada na EPI e a que se fez referência anteriormente, de tal sorte que o Estado figura como agente central nas relações internacionais para ambas as perspectivas teóricas.

Alguns poderiam afirmar que decorreria do fato de que a TRI não tem por objeto e, nessa medida, por finalidade 
compreender os problemas econômicos em si e por essa razão não teria por que compreender as relações e os fenômenos que se realizam entre agentes individuais dando corpo ao mercado. No entanto, essas relações e estes fenômenos permeiam absolutamente o estudo das relações internacionais e são por isso também objeto de sua observação e, em grande parte, interpretação ou análise. O que parece distinguir os dois campos, portanto, é a forma como os diferentes interesses dentro das sociedades nacionais e suas relações com interesses fora delas são encaminhados.

Assim, por exemplo, se para o "realismo clássico" o sistema internacional é uma unidade cujo funcionamento se orienta por um reduzido número de interesses, sendo estes basicamente os da paz e da seguridade, não há como não pensar que os fatos econômicos sejam importantes para sua consecução, dando margem a diferentes possibilidades de relacionamentos na realidade internacional. Mas o que marca essa visão do ordenamento das relações internacionais é que os diferentes interesses manifestos na realidade são encaminhados por um número reduzido de atores da mesma natureza, o Estado ou seus representantes, e os recursos disponíveis para sua consecução são restritos, o que acaba por vincular na maior parte das vezes as questões econômicas e militares.

No caso do "idealismo puro", por outro lado, se a razão se sobrepõe à força para poder se estabelecer a paz, a guerra se desvincula, pelo menos imediatamente, dos interesses de Estado e os diferentes interesses manifestos na realidade internacional tem fruição menos restrita, dado que os recursos disponíveis para sua vazão são mais variados. Mesmo assim tais interesses são encaminhados pelo Estado.

Ainda, mesmo as concepções mais atuais da TRI tais como o neo-rrealismo e o neo-institucionalismo e suas derivações, desenvolvidas a partir da II Grande Guerra, consideram que as questões econômicas ocupam espaço pronunciado como móvel na determinação das relações internacionais. E estas questões não se desvinculam da ação dos Estados que, mesmo com protagonismo reduzido, figuram como um ator fundamental no ordenamento internacional.

No que concerne à EPI, entretanto, a dicotomia entre as relações de Mercado e relações de Estado se manifesta claramente na maior parte dos estudos econômicos que se autointitulam de Economia Política Internacional, inclusive naqueles que se enquadram na perspectiva do atual mainstream no pensamento econômico, fazendo com que a produção de conhecimento nesse novo campo, cuja responsabilidade deve recair sobre o economista, fique restrita à análise e a observação das relações exclusivas de Mercado ou de Estado e, por consequência, assuma um caráter insuficiente para a explicação da realidade internacional em sua totalidade. Como afirma o próprio Gilpin em trabalho posterior:

\section{Morgenthau's writings, in fact, attacked unbridled nationalism [...]. The point, however, for Morgenthau and other realists (myself included), is that realism and natio- nalism are not identical (GILPIN, 2001, p. 15.}

Nessa mesma perspectiva Gilpin afirma que, a despeito das mudanças porque tem passado o mundo desde a década de 70 do século passado, a economia internacional e a política internacional, enquanto áreas de conhecimento especializadas na interpretação dos fenômenos mundiais, mantem separadas as esferas do Estado e do mercado. E essa separação dá o tom da EPI.

Para o autor, essas esferas correspondem a duas formas de organização social que não devem se excluir mutuamente e, no entanto, são vistas de formas diferentes pela política e pela economia. Embora estas correspondam a duas forças distintas, isto é, compreendam o ordenamento da atividade humana como promovido por ações de naturezas diversas, 
não são independentes e, inclusive, mantem relação funcional. E uma vez que essa separação acontece, o objeto de estudo por excelência da EPI fica prejudicado, impedindo seu desenvolvimento enquanto corpo de conhecimento autônomo e especializado. Por isso mesmo o autor afirma que convém

\section{[...] usar o termo 'economia política' apenas para indicar um conjunto de questões que devem ser examinadas com uma mistura eclética de métodos analíticos e perspecti- vas teóricas (GILPIN, 2002, p. 10).}

Assim, se para os liberais o livre-comércio promove a harmonia, para os nacionalistas fica acentuada a natureza conflitiva das relações econômicas, considerando a distribuição da riqueza o resultado das relações exclusivamente de poder, sendo estas uma prerrogativa de Estado. A questão fica polarizada entre representações da realidade em torno das ideias segundo as quais o Estado é um entrave ao funcionamento do mecanismo de preços, ou o mecanismo de preços simplesmente mascara as relações políticas que dão forma ao Estado.

Por essa razão, para o próprio Gilpin, a integração da economia internacional e da política internacional é um imperativo da realidade contemporânea, o que o motiva mesmo a definir a EPI como "[...] a interação recíproca e dinâmica [...] da busca da riqueza e do poder" (GILPIN, 2002, p. 28).

Ao que parece a diferença crucial entre poder e riqueza passa despercebida em boa parte do que se produz naquilo que se considera o campo da EPI de tal maneira que ao tratar das questões econômicas internacionais os economistas pensam muitas vezes estar construindo uma interpretação da realidade internacional como um todo. Esquecem-se de que a riqueza é um meio fundamental para se alcançar poder, mas que o poder é fundamental para a aquisição de riqueza. Isso se manifesta nitidamente na maneira co- mo trabalham seus temas e em conceitos tais como o de vulnerabilidade.

Conforme se demonstrou anteriormente, ainda que de maneira muito breve, para a política internacional, ou mais especificamente para a TRI, as relações políticas não podem ser excluídas de qualquer interpretação da realidade e a economia tem sempre algum destaque nesse processo. Em outras palavras, a integração entre a política e as questões econômicas está presente na elaboração da interpretação da realidade internacional nessa área de conhecimento. A EPI, portanto, deve prestar algum tributo a TRI na busca de sua autonomia.

Cabe, para reforçar este argumento, lembrar que Gilpin se apoia sobremaneira no pensamento de Morgenthau, importante realista moderno, que em sua obra fundamental A Política entre as Nações, no Capítulo 1- Uma Teoria Realista da Política Internacional - ao arrolar seis princípios do realismo político, afirma no último deles:

\section{O realista político não ignora a existência nem a relevância de padrões de pensamen- to que não sejam ditados pela política. $\mathrm{Na}$ qualidade de realista político, contudo, ele tem de subordinar esses padrões aos de caráter político [...] (MORGENTHAU, 2003, p. 2).}

Já para neoinstitucionalistas como Keohane e Nye essa relação se torna questão nuclear visto que em sua interpretação da realidade internacional tomam por empréstimo elementos conceituais considerados fundamentais na economia.

Os motivos para a separação entre a realidade econômica e a realidade política, embora tal separação contrarie o escopo dos objetivos de uma verdadeira EPI no sentido de encontrar meios de trabalhar articuladamente esses aspectos do mundo real, se manifestam de forma relativamente clara e alguns deles passam a ser indicados brevemente a seguir. 
Em primeiro lugar, as interpretações da realidade na EPI incorporam as concepções metodológicas subjacentes ao pensamento econômico tradicional e, nessa medida, procuram tratar os problemas não estritamente econômicos ou como problemas eminentemente econômicos, ou como "variáveis exógenas", sobre as quais não se pode exercer controle e que, por conseguinte, não merecem atenção. Mais uma vez, daí devem se excluir as concepções de EPI de vertente marxista.

Este parece ser, por exemplo, o caso das questões relativas à segurança internacional que na visão de Strange (1984; 1997), tendo como parâmetro a expressão militar do poder, não podem ser desconsideradas nas relações entre as nações e que são normalmente desprezadas pelos economistas em suas interpretações sobre a realidade internacional. Isto significa dizer que os trabalhos que se pretendem enquadrar no campo da EPI não podem absolutamente se abster da necessária articulação entre as variáveis riqueza e poder, isto é, não podem desconsiderar as relações internacionais como relações totalmente permeadas por questões econômicas e políticas.

Como afirma o próprio Gilpin:

A expressão 'economia política' sofre de ambiguidade. Adam Smith e os economistas clássicos a utilizaram com o sentido do que hoje chamamos de 'ciência econômica'. Mais recentemente, alguns estudiosos como Gary Becker, Anthony Downs e Bruno Frey definiram 'economia política' como a aplicação da metodologia da economia formal, ou seja, o chamado 'modelo de ator racional', a todos os tipos de conduta humana (GILPIN, 2002, p. 25).

Na realidade, isso faz parte de um contexto mais amplo e mais grave em que se insere a produção de conhecimento na área da Economia, particularmente na atualidade. Esta parece estar infensa ao que se pensa e se produz em outros campos das Ciências Humanas e Sociais, julgando deter os meios necessários para a compreensão da realidade em sua totalidade e se colocando numa posição de autossuficiência absoluta.

Por outro lado, do ponto de vista metodológico, o fato de as interpretações da realidade na EPI incorporarem concepções metodológicas inerentes ao pensamento econômico tradicional, excetuando-se também como se afirmou anteriormente aquelas da corrente marxista, faz com que carreguem um nítido traço apriorista e teleológico, dificultando o desenvolvimento de um método mais apurado que conceda ao conhecimento da EPI um status científico, com consequente autonomia.

É interessante ressaltar, nesse sentido, as importantes colocações de Georg Friederich List, autor pouco explorado no estudo do pensamento econômico talvez até por sua sustentação de uma das ideologias da EPI, a do nacionalismo, que claramente põe a questão nos devidos termos, referindo-se à natureza do pensamento econômico clássico de Adam Smith sobre a realidade internacional. Em seu Sistema Nacional de Economia Política afirma:

\footnotetext{
Preparei-me estudando obras sobre Economia

Política. [...] A teoria corrente inculcava o princípio da liberdade de comércio. [...] Dei-me conta de que a teoria popular não considerava as nações, mas simplesmente, de um lado, a humanidade inteira, ou os indivíduos, do outro. Percebi claramente que a livre concorrência entre duas nações altamente civilizadas só pode ser mutuamente benéfica no caso de ambas estarem em um grau de desenvolvimento industrial mais ou menos igual; [...] Em uma palavra, dei-me conta da distinção entre a Economia Cosmopolítica e a Economia Política (LIST, 1983, p. 3,4).
} 
A arguta observação do autor revela o recorrente viés do pensamento econômico que, em sua maior parte ainda nos dias de hoje, teima em tomar a parte pelo todo e manifestando uma necessidade de aportar os problemas humanos com um corte metafísico, vê o comportamento individual como a expressão acabada do comportamento dos homens em coletividade.

O que se pode concluir de tudo isso, ao que tudo indica, é que os estudos da EPI numa perspectiva não-marxista, sofrem de um mal congênito de tal maneira que tomada simplesmente como o estudo das relações econômicas internacionais, ou economia internacional, a EPI é impedida de sair de seu estado incipiente enquanto campo específico de conhecimento. Mais do que isso, muitas vezes se transformam em peças retóricas de caráter ideológico no sentido de mascarar a realidade.

Isso, entretanto, não invalida os esforços dispendidos com o sentido de se alcançar um método que confira a EPI a condição de conhecimento especializado. Com esse objetivo, parece recomendável que se inicie, conforme se fará adiante, com um breve recuo aos pensamentos de alguns autores destacados na economia que, ainda que fora da perspectiva do estudo sistemático da EPI, acabaram por construir o arcabouço teórico que daria sustentação a um processo de desenvolvimento de interpretações articuladas da realidade internacional, dando corpo a uma real EPI.

Numa primeira visada e de maneira simplificada, podem ser indicados, como já se fez ao longo deste texto, autores como Adam Smith, David Ricardo, Georg List e John Maynard Keynes.

Os primeiros três por fundarem os estudos econômicos sobre as relações entre nações, ainda que se posicionando conforme as críticas aqui colocadas, isto é, ou assumindo perspectivas ideológicas antagônicas acerca das questões internacionais, ou não estabelecendo relações efetivas entre economia e política ou Mercado e Estado, mas colocando seus estudos no âmbito da economia política, dão a partida para o estudo de EPI, destacando de princípio a necessidade e a importância do desenvolvimento de um conhecimento especializado sobre esse aspecto da realidade.

A partir disso, inclusive, é possível dizer que o tema por excelência da EPI é o desenvolvimento, uma vez que este deriva da distribuição de riqueza dentro das nações e entre as nações. Diferentemente da colocação geral no estudo da EPI na atualidade, não basta avaliar os fluxos de comércio, o investimento e a tecnologia realizados na realidade internacional, mas estudá-los à luz daquilo que produzem, isto é, riqueza ou pobreza, justiça ou injustiça, liberdade ou opressão. E, nessa direção, é fundamental se compreenderem os processos políticos e a dimensão do poder que dão substância às decisões econômicas.

Keynes, por sua vez, ao incorporar estes elementos à sua análise da realidade europeia pós - $1^{\mathrm{a}}$. Grande Guerra, se encontra claramente identificado com a proposta de constituição da EPI, na condição de campo de conhecimento relevante.

Para finalizar estas considerações, embora o estudo organizado da EPI ainda se encontre em estado incipiente, uma dívida se coloca para com alguns economistas que, procurando superar os entraves aludidos ao desenvolvimento desse campo de conhecimento, envidaram esforços no sentido de construir uma EPI e que por isso, como acontece com o pensadores marxistas, merecem estudo à parte. Cabe destaque, nesse sentido, para as obras de Charles Kindleberger, Robert Gilpin e Susan Strange.

A título de contribuição, uma breve explanação de aspectos importantes para o desenvolvimento da EPI de pensamentos dos autores originais clássicos aqui indicados é procedida a seguir. 


\section{3_Adam Smith e o Liberalismo Econômico}

Adam Smith nasceu numa família de classe média na Escócia em 1723 e faleceu em 1790. Entrou no curso de Humanidades da Universidade de Glasgow em 1737 e a partir de 1748 passou a ministrar uma série de cursos e conferências em Edimburgo, cujos temas envolviam, inclusive, questões relacionadas aos problemas econômicos, problemas esses que já eram tratados com base numa enfática defesa do livre mercado.

Tais incursões junto ao meio acadêmico fizeram com que Smith, em 1751, assumisse temporariamente as cadeiras de Lógica e de Filosofia Moral na Universidade de Glasgow e em 1752 fosse efetivado como professor de Filosofia Moral da mesma Universidade. Pode-se afirmar que a partir de então Smith solidificou sua carreira, sobretudo como pensador no campo da Economia Política, o que lhe abriu portas para atuar junto à elite intelectual de seu país ainda muito jovem.

A primeira grande obra de Smith, Teoria dos Sentimentos Morais, foi publicada em 1759. Era um amplo projeto literário relacionado não apenas aos temas desenvolvidos na disciplina de Filosofia Moral em Glasgow, mas que também continha uma série de princípios de economia e de política econômica que mais tarde comporiam a sua principal obra.

Em 1766 passou a se concentrar na elaboração de sua principal obra, A Riqueza das Nações, publicada em 1776, que influenciou não apenas o estudo da Economia Política, mas também os partidos políticos e os debates no Parlamento britânico da época, obviamente pela sua perspectiva liberal para o tratamento das questões econômicas.

De maneira geral, pode-se afirmar que o denominador comum dos princípios liberais entre os mais diversos autores dessa vertente é a ênfase dada ao livre intercâmbio econômico entre as nações que, segundo suas proposições, quando efetivado permite a existência de relações pacíficas, harmoniosas e cooperativas entre elas. Isto porque o sistema de mercado baseia-se num contexto de interde- pendência simbiótica, que se materializa pela geração de benefícios econômicos recíprocos.

Tais considerações podem ser identificadas na Rique$z a$ das Nações, que logo nos seus primeiros capítulos (sobre o valor das mercadorias) desenvolve a relação entre a riqueza de uma nação e o grau de aprimoramento das forças produtivas. Segundo o autor, tal relação está associada à divisão do trabalho, que por sua vez está condicionada à extensão dos mercados, o que se explica pelo fato de que:

Como éo poder de troca que leva à divisã do trabalho, assim a extensão dessa divisão deve ser sempre limitada pela extensão desse poder, ou, em outros termos, pela extensão do mercado. Quando o mercado é muito reduzido, ninguém pode sentir-se estimulado a dedicar-se inteiramente a uma ocupação, porque não poderá permutar toda a parcela excedente de sua produção que ultrapassa seu consumo pessoal pela parcela de produção do trabalho alheio, da qual tem necessidade (SMITH, 1996, p. 27).

Nesse sentido, fica latente a posição do autor em defender a ampliação das relações de comércio internacional como uma condição indispensável para viabilizar o aumento da capacidade produtiva do trabalho, o que para a lógica smithiana da mão invisível leva ao incremento da riqueza pessoal e, por conseguinte, à prosperidade geral de uma nação.

Essa lógica busca refutar de maneira sistemática o modelo mercantilista, ao desacreditar a sua proposição básica de que o protecionismo representa um mecanismo ideal para a viabilização do acúmulo de metais. Contrapondo-se a essas conjecturas, 0 autor faz uma efusiva defesa da liberdade comercial, destacando, entre outras coisas, que essa 
seria uma condição necessária para uma nação alcançar um bom desempenho econômico, caso contrário:

\section{[...] a atividade do país é desviada de um} emprego mais vantajoso de capital e canalizada para um emprego menos vantajoso, consequentemente, o valor de troca da produção anual do país, ao invés de aumentar [...] necessariamente diminui, por força de cada norma que imponha tais restrições à importação (SMITH, 1996, p. 439).

Argumenta ainda que:

Enquanto um dos países tiver estas vantagens, e outro desejar partilhar delas, sempre será mais vantajoso para este último comprar do que fabricar ele mesmo. [...] Uma vez que, [...] proibir, por uma lei perpétua, a importação de trigo e gado estrangeiros, na realidade equivale a determinar que a população e a atividade de um país nunca devem ultrapassar aquilo que a produção natural de seu solo tem condições de sustentar (SMITH, 1996, p. 439-440).

Desse modo, Smith (1996) postula que a adoção de um mecanismo de funcionamento da economia baseado no sistema de liberdade econômica não só viabiliza o acesso aos produtos importados mais baratos, como também evita a existência de atividades econômicas que não apresentam vantagens "naturais", o que contribui para o desenvolvimento das forças produtivas e, consequentemente, para o processo de enriquecimento de uma nação.

$\mathrm{O}$ autor, ao fazer tais proposições, buscou se basear nos princípios fundamentais que norteariam o sentido humano nas suas relações com os objetivos individuais e nas consequentes vantagens sociais da liberdade plena, sendo que tais proposições são consideradas uma reafirmação da concepção do liberalismo burguês de Locke (1978), que relaciona a influência da liberdade natural ao grau de riqueza dos indivíduos e da sociedade, fatores esses considerados determinantes à existência de uma sociedade verdadeiramente harmônica.

Cabe ressaltar que as suposições acerca do comportamento individual no pensamento liberal estão fundamentadas tanto no estado natural lockeano quanto na crença de que os atos humanos estão sempre impregnados de virtudes (HUME, 1999). Baseado nisso, Napoleoni considera que nasce com Smith o:

\section{[...] verdadeiro fundamento da sociedade civil e, portanto, como o princípio da pró- pria existência da realidade do Estado, na qual é essencialmente exigida a garantia das condições que são necessárias ao exer- cício ordenado da produção, da troca e do consumo (NAPOLEONI, 1991, p. 47).}

Essas breves considerações enfatizam que as principais contribuições da teoria smithiana acerca da liberdade econômica estão centradas na importância da ampliação das relações econômicas entre as nações e na organização de um Estado cujos atos não podem nem devem afetar o bom funcionamento dos mercados.

Portanto, não se deve observar essa parte da obra de Smith exclusivamente como uma teoria de comércio internacional que trata dos benefícios de um sistema liberal de exportações e de importações, ou apenas como mera proposição de uma política interna que visa regular as relações de comércio entre diferentes países. Complementarmente, deve-se levar em consideração que a obra de Smith também compõe uma conjunção de fatores que permeia as relações entre os Estados, relações estas intrínsecas às respectivas políticas econômicas externas. Neste sentido, vale notar que para o autor: 
[...] a riqueza de uma nação vizinha, embora seja perigosa na guerra e na política, certamente é vantajosa para o comércio. Em estado de hostilidade, essa riqueza dos vizinhos pode possibilitar aos nossos inimigos manterem esquadras e exércitos superiores aos nossos; mas em estado de paz e de comércio essa riqueza também pode possibilitar-lhes trocar conosco um valor maior de mercadorias, $e$ proporcionar-nos um mercado melhor, seja para a produção direta do nosso próprio país, seja para tudo aquilo que se compra com essa produção (SMITH, 1996, p. 472).

Tal perspectiva se pauta no fato de que o grande objetivo da economia política de um país (hoje denominada política econômica) consiste em aumentar sua riqueza e seu poder, o que compõe o elemento basilar da Economia Política Internacional. Para tanto, os seus diversos setores produtivos devem atuar de acordo com o curso normal dos acontecimentos, evitando, assim, a geração de desigualdades econômicas e sociais.

\section{4_David Ricardo e o Comércio Internacional como representação do mundo}

David Ricardo nasceu em Londres em 1772 e faleceu em 1823, pertencente a uma rica família de comerciantes e banqueiros, desde muito cedo conviveu no mundo dos negócios e das finanças.

Atuou como político, ao eleger-se representante na Câmara dos Comuns em 1819. Durante sua atuação política Ricardo exerceu grande influência sobre o debate político e econômico da sociedade britânica à época.

Ricardo não teve qualquer formação formal após completar quatorze anos. No entanto, buscou, por conta própria, se aprofundar no estudo de diversos temas, com destaque para os relacionados à economia política. Foi quando se debruçou sobre as obras de Adam Smith.

A importância de David Ricardo para a Economia Política é destacada, pois além de solucionar algumas incongruências teóricas de Smith no que tange à teoria do valor, contribuiu para a elaboração de uma teoria mais consistente de comércio internacional, que passou a ser amplamente difundida pelos defensores do processo de liberalização econômica, bem como rebatida por seus críticos.

A época em que Ricardo viveu foi marcada pelos avanços tecnológicos e pelas mudanças sociais que culminaram na Primeira Revolução Industrial, inaugurando uma nova fase do capitalismo inglês, marcado não apenas pelo desenvolvimento da economia local, como pela ampliação da miséria e da mortalidade entre classes trabalhadoras, o que também foi objeto de análise do autor.

Ideologicamente Ricardo foi fortemente influenciado pela Revolução Francesa de 1789, cujos ideais eram tidos como essenciais para a nova disposição da vida social que passou a vigir na Europa. Tais princípios, calcados no liberalismo político, compunham um dos pilares das perspectivas teóricas que formam os princípios da livre concorrência.

Baseando-se nessas proposições, Ricardo tornou-se um dos principais defensores do liberalismo econômico, cuja influência sobre o mundo acadêmico dispensa apresentações.

Uma das principais contribuições teóricas de Ricardo, que particularmente guarda relação com o presente artigo, está associada ao debate sobre a Lei dos Cereais, de 1815, que serviu de base para a elaboração de sua principal obra Princípios de Economia Política e Tributação, publicada em 1817.

Contrário à Lei dos Cereais, que visava proteger os produtores domésticos de cereais da concorrência externa, Ricardo argumentou que tal prática contribuía para que os lucros dos capitalistas fossem deprimidos, o que levaria à 
diminuição do nível de acumulação de capital e, por conseguinte, afetaria negativamente o crescimento da economia.

Nesse sentido, o autor defendia enfaticamente a adoção do livre comércio entre as nações como uma maneira de reverter não somente a tendência declinante das taxas de lucros, mas também da taxa de crescimento econômico. Essa discussão faz parte de sua extensa descrição acerca da teoria da distribuição da renda.

Deve-se ressaltar, no entanto, que os interesses envolvendo a Lei dos Cereais contrapunham os industriais e as populações urbanas aos produtores agrícolas e aos proprietários de terras, e que Ricardo assumia posição bastante enfática de defesa desses emergentes interesses industriais.

Ricardo se opôs à Lei dos Cereais, buscando argumentar não só do ponto de vista teórico, mas também pela atuação política junto ao Parlamento britânico. Apesar de sua enfática luta política e retórica para acabar com o protecionismo inglês, a Lei dos Cereais perdurou até 1846 .

Sua mais importante e consistente proposição em defesa do liberalismo no comércio internacional está presente na Teoria das Vantagens Comparativas. Tratando especificamente da discussão acerca das vantagens do comércio internacional, essa teoria busca expor, do ponto de vista lógico, como o livre comércio entre duas nações é benéfico para ambas.

Para Ricardo, um país que realiza trocas com outro não necessita ter vantagens absolutas na produção de uma mercadoria, ou seja, ter uma atividade produtiva mais eficiente ao empregar menor quantidade de trabalho. $\mathrm{O}$ que importa é a existência de uma vantagem relativa na produção, o que implica identificar a razão entre o tempo de trabalho entre distintas mercadorias produzidas, de tal modo que se possam comparar essas quantidades relativas entre diferentes países. Dessa forma:
Num sistema comercial perfeitamente livre, cada país naturalmente dedica seu capital e seu trabalho à atividade que lhe seja mais benéfica. Essa busca de vantagem individual está admiravelmente associada ao bem universal do conjunto dos países. Estimulando a dedicação ao trabalho, recompensando a engenhosidade e propiciando o uso mais eficaz das potencialidades proporcionadas pela natureza, distribui-se o trabalho de modo mais eficiente e mais econômico, enquanto, pelo aumento geral do volume de produtos, difunde-se o benefício de modo geral e une-se a sociedade universal de todas as nações do mundo civilizado por laços comuns de interesse e de intercâmbio. Este é o princípio que determina que o vinho seja produzido na França e em Portugal, que o trigo seja cultivado na América e na Polônia, e que as ferramentas e outros bens sejam manufaturados na Inglaterra (RICARDO, 1996, p. 97).

Essa abordagem ricardiana do comércio internacional vem influenciando diversos autores, apesar das diferenças teóricas que se referem à teoria do valor trabalho.

Cabe destacar que Ricardo também defendia em sua obra, porém de forma mais discreta, a livre mobilidade dos capitais, como meio de equalizar as relações capitalistas entre os países. Para o autor:

Em um mesmo país, os lucros, de maneira geral, se situam sempre no mesmo nivel, ou diferem somente na medida em que o emprego de capital pode ser mais ou menos seguro e atraente. Não ocorre o mesmo entre diferentes países. Se os lucros do capital empregado em Yorkshire fossem maiores do que os do capital empregado em Londres, este rapidamente se 
deslocaria de Londres para Yorkshire e assim

os lucros se igualariam (RICARDO, 1996, p. 97).

Tais perspectivas tornaram-se basilares para a elaboração de diversas teorias de comércio internacional, inclusive críticas, bem como para inúmeras discussões que buscam compreender as relações econômicas entre diferentes nações. E, de acordo com Fusfeld, uma das principais contribuições da Teoria das Vantagens Comparativas de Ricardo foi a sua aplicabilidade às relações econômicas internacionais, uma vez que:

\section{[...] uma análise da economia doméstica baseada nos fundamentos da terra, trabalho e capital podia ser aplicada de maneira rigorosa às relações econômicas internacionais. Isso representou um grande passo adiante no desenvolvimento do estudo da economia como ciência social. Um dos objetivos de todo avanço científico é a construção de generalizações mais amplas possiveis e que abranjam o mais vasto conjunto de fenômenos. Uma disciplina progride ao desfazer-se de detalhes e construir princípios gerais. Ricardo fez isso com a econo- mia, ao reduzir todos os fenômenos econômi- cos às relações fundamentais entre fatores de produção (FUSFELD, 2001, p. 61).}

Ricardo se tornou uma referência não apenas no que tange às teorias de comércio internacional, mas também como árduo causídico do liberalismo econômico, tendo mesmo influenciado boa parte das políticas de comércio na Grã-Bretanha a partir de meados do século XIX.

Porém, é possível identificar no modelo ricardiano algumas dissensões em relação ao objeto de estudo da Economia Política Internacional. O primeiro deles diz respeito ao fato de que a Teoria das Vantagens Comparativas não contempla algumas variáveis que ajudam na compreensão da dinâmica que levou à superioridade tecnológica da Grã-Bretanha à época, condição alcançada pelo menos meio século antes de seus vizinhos, o que permitiu ao país adotar as técnicas mais modernas e eficientes de produção.

O outro ponto reside na incongruência que tal proposição teórica carrega ao sopesar que a superioridade no desenvolvimento capitalista se explica exclusivamente pela adoção de um sistema de livre mercado. Na verdade, tal ajuizamento carece de uma explicação mais ampla, que recorra, por exemplo, às avaliações históricas e políticas, até porque parte do desenvolvimento econômico e social da Grã-Bretanha também está associado às suas conquistas coloniais e a exploração de mercados privilegiados oriundos de relações internacionais antagônicas a quaisquer proposições liberais.

Ademais, segundo Denis (2000), esses, entre outros fatos, evidenciam que Ricardo adotou um ponto de vista materialista da filosofia utilitarista, de tal modo que não foi capaz de compreender a verdadeira natureza do modo de produção capitalista, dado que tratou as leis econômicas como basicamente naturais e de um alcance universal. Ao fazê-lo, Ricardo parece, mais uma vez, subestimar a proeminência das relações de poderes entre as Nações.

É em função dessa perspectiva que se pode afirmar que a Teoria das Vantagens Comparativas de David Ricardo é um modelo de comércio internacional, ou seja, não contempla os objetos de estudo da Economia Política Internacional, que, de acordo com Gonçalves:

\section{[...] procura superar essa limitações específicas} de cada campo teórico ao apresentar um enfoque analítico eclético ou abrangente para os fenômenos próprios do sistema internacional, em geral, e do sistema econômico internacional, em particular. Esse enfoque eclético 
remonta, na realidade, ao entendimento da Economia Política não como um corpo teórico fechado com as leis de aplicação universal, mas, sim, como a aplicação da teoria aos problemas do mundo real com a ajuda de outras ciências sociais (GONÇALVES, 2005, p. 4-5).

Portanto, a discussão de Ricardo acerca das relações econômicas internacionais está restrita à ótica economicista das vantagens do comércio internacional, não obstante sua obra tenha influenciado os mais diversos matizes teóricos das ciências sociais, bem como sua atuação política no Parlamento inglês tenha sido de uma concretude que não deve ser descartada.

\section{5_Georg List e a Economia Política Nacional}

Georg Friedrich List, economista político alemão, nascido em 6 de agosto de 1789 em Württemberg, e morto no dia 30 de novembro de 1846 na cidade de Kufstein. Ao contrário da maioria dos grandes economistas, List foi além de um grande intelectual, um homem militante e de ação. Observa-se que sua obra foi claramente conduzida pelos caminhos tortuosos percorridos em vida, passando de agitador à jornalista, e de homem de negócios a pensador.

List nasceu num momento extremamente conturbado da Europa, 15 dias após a tomada da Bastilha na França, entre a Primeira e a Segunda Revolução Industrial e numa "Alemanha" semi-feudal composta por diversos principados, ducados e cidades livres. Cresceu e se formou exatamente no momento em que o capitalismo se consolidava como o sistema econômico dominante na Europa e se espalhava para os demais continentes, com a Inglaterra garantindo sua posição de nação econômica e militarmente hegemônica, e nas Américas, os Estados Unidos se desenvolvendo de maneira impressionantemente rápida e revolucionária em relação ao modelo europeu.
Em seu primeiro cargo público, List escreve um ensaio que já incluía a filosofia político-econômica, um dos pilares de suas obras. Considerou a nação como a unidade central, tanto para análises teóricas como para formulações de políticas, demonstrando assim a grande conexão entre teoria e prática no pensamento do autor. Ao mesmo tempo, confrontou o que ele chamou de "cosmopolitismo" da escola econômica liberal, já dominante no período.

A forma panfletária de seus escritos, juntamente com a linguagem direta empregada, deixa muito clara a preocupação de uma metodologia objetiva e a intenção prática do conhecimento. Após uma série de críticas ao seu modelo de ensino que visava mais as questões práticas do que a teoria econômica, List funda o jornal Volksfreund aus Schwaben, ${ }^{1}$ que defendia importantes reformas políticas na Alemanha de seu tempo.

Mais tarde, List declarou que foi seu trabalho de professor e jornalista que o levou a ter grandes dúvidas sobre a validade universal do livre comércio, criando então a primeira noção da diferença entre "economia cosmopolítica" e "política econômica nacional", e a ter a certeza que o futuro econômico da Alemanha se encontrava no estabelecimento de uma união aduaneira que eliminasse as tarifas internas entre os vários Estados que a compunham, criando tarifas para as trocas de mercadorias com os outros países do mundo. Esta é a origem da revolucionária ideia do Zollverein, ${ }^{2}$ lançada por seu jornal.

Nos Estados Unidos, List realizou seu desejo de estudar o sistema econômico americano, sendo apresentado às mais altas autoridades do país como Henry Clay, Harrison, Jefferson, Madison e Emerson. Lá, List observou a cristalização de suas críticas ao "cosmopolitismo" de Adam Smith. Desde 1792, Hamilton, então secretário do Tesouro americano, divulgava seu importante Report on Manufactures ${ }^{3}$ em que defendia o uso, de forma temporária, de tarifas protecionis- 
tas para amparar as indústrias nascentes, criando um mercado interno protegido das indústrias europeias.

Ao iniciar sua jornada no processo de formulação dos destinos da economia norte-americana, List escreveu um documento de defesa do protecionismo industrial a ser apresentado na Convenção Nacional dos Protecionistas em 30 de julho de 1827. Com este trabalho, apresentado a Charles Jerrel, e as suas doze letters ${ }^{4}$ publicadas no Philadelphia National Journal, List elaborou o fundamento do que depois veio a ser chamado de "seu sistema" numa publicação com o título Outlines of a New System of Political Economy. Em seu conteúdo já se encontra toda a essência de sua mais reconhecida obra publicada em 1841, o Sistema Nacional de Economia Política.

Obcecado pela ideia de criar malhas ferroviárias para o desenvolvimento da Alemanha, List retorna à Europa em 1830, desembarcando em Havre a caminho de Hamburgo, onde ocuparia o cargo de cônsul dos EUA. Em outubro de 1831, List viajou novamente aos EUA e obteve o novo posto de cônsul em Leipzig, passando a se dedicar exclusivamente aos seus estudos e à construção de um sistema de linhas férreas em seu país de origem.

Após a recusa de seu ensaio Quando uma Nação se propõe a estabelecer a liberdade de comércio ou de modificar sua legislação aduaneira, quais são os fatos que ela deve tomar em consideração para conciliar da maneira mais equilibrada possível os interesses dos produtores e das massas de consumidores? para um concurso promovido pela Academia de Ciências Políticas de Paris, List transformou sua indignação em força, dizendo ter descoberto que todas suas ideias orientadas à nação alemã poderiam ser transformadas num sistema coerente e de validade universal e que ele teria criado, sem saber, uma teoria básica do processo de indução do desenvolvimento das nações economicamente atrasadas, sendo o ponto de partida para a elaboração de seu "Sistema”.

Em 1840, logo após a morte de seu único filho homem, List retorna à Alemanha se empenhando no término de seu grande livro, concluído em maio de 1841 sob o título de O Sistema $\mathrm{Na}$ cional de Economia Política: Comércio Internacional, Política Comercial e a União Aduaneira Germânica. Olivro teve excelente recepção, e seus seguidores o apoiaram na formação de um seminário que visava discutir a formação da união aduaneira alemã que sempre defendeu.

Um mês após uma viagem para promover a criação da Sociedade de Indústria e Comércio da Baviera, List permaneceu na cidade de Kufstein, onde na manhã do dia 30 de novembro, saiu a um "passeio" no meio do bosque e se suicidou com um tiro no peito aos 57 anos de idade.

O estudo do pensamento econômico de Georg Friedrich List, principalmente sua obra mais importante, O Sistema Nacional de Economia Política, se faz essencial para a atual discussão em Economia Política Internacional. Chega ser impressionante a atualidade dos questionamentos feitos pelo autor ao longo de sua obra. Todos esses questionamentos ainda continuam em pauta, tanto nas contendas acadêmicas como nos noticiários e debates políticos da atualidade.

A discussão entre liberalismo e protecionismo econômico não é recente. Podemos remontá-la pelo menos à polis grega. Porém, no sentido moderno de nação tal discussão tem início com os clássicos da filosofia moderna com David Hume e John Locke, defensores do liberalismo e, do outro lado, os mercadores e os estadistas defensores do protecionismo, conforme se assinalou anteriormente. É exatamente neste contexto que List se insere. Cercado de intelectuais e políticos alemães seguidores dos ideais econômicos liberais ingleses, sua grande tarefa era demonstrar quais seriam os erros da teoria econômica dominante e as causas fundamentais que levam a tais. 
Logo no prefácio do Sistema, List explicita quais foram os motivos que o levaram a iniciar sua investigação no plano econômico. Em 1818 a Alemanha sofre grande queda no bem-estar social, e o autor inicia seus estudos em Economia Política e começa a travar contato com os teóricos liberais ingleses, principalmente Adam Smith e David Ricardo. Todavia, List diz:

\section{[...] não encontrei satisfação em ensinar aos jovens esta ciência em sua forma atual; queria ensinar-lhes também qual é a polí- tica econômica que possibilite promover o bem-estar, a cultura e o poder da Alemanha (LIST, 1983, p. 3).}

A grande contradição neste raciocínio, segundo List, eram os efeitos positivos do sistema continental implementado por Napoleão, sistema este extremamente protecionista, e nos resultados catastróficos de seu término para a França, contradizendo dessa maneira toda a teoria econômica defensora do livre comércio. De forma completamente inovadora, List propõe a divisão de toda a teoria econômica existente em dois grupos: Economia Política e Economia Cosmopolítica.

Para o autor, antes de Quesnay e dos economistas franceses, existia apenas uma prática de economia política, ou melhor, não havia até então ninguém que houvesse teorizado sobre esse tema. Servidores públicos, administradores e pensadores que escreviam sobre matérias de administração pública e ocupavam-se com os problemas da agricultura, manufatura, comércio e navegação dos países aos quais pertenciam sem fazer nenhuma análise sobre as causas da riqueza. Estes estavam interessados apenas com os problemas nacionais, e não com os interesses de toda humanidade (LIST, 1983).
Quesnay foi o primeiro a se dedicar ao estudo sobre a origem e as causas da riqueza, entretanto, ele o fez de maneira universal, excluindo completamente os interesses nacionais da problemática econômica, originando a ideia de um comércio universal e livre. Quesnay passa a exigir, nas palavras de List, "[...] que imaginemos que os comerciantes de todas as nações formam uma única república comercial” (LIST, 1983, p. 89).

List denominou essa escola de pensamento econômico de Economia Cosmopolítica, isto é, conjunto de teorias econômicas que se baseiam na ideia que toda a humanidade pode atingir a prosperidade conjuntamente. Para o autor, tais teóricos excluem totalmente o conceito de nação de suas teorias, opondo-se assim a Economia Política, ciência que se propõe a investigar como determinada nação pode alcançar a prosperidade, a civilização e o poder, dadas as condições vigentes no mundo. De forma completamente contrária à Economia Cosmopolítica, na Economia Política o conceito de nação é o centro e o objeto de análise principal de toda a teoria.

Contrariando o senso comum, List não enquadra a teoria econômica de Adam Smith como Economia Política, mas sim como Economia Cosmopolítica, dado que o autor constrói sua teoria de modo extenso, tentando demonstrar o conceito cosmopolítico da liberdade absoluta de comércio para todas as nações. Nas palavras de List:
Adam Smith se preocupa tão pouco quanto
Quesnay com a verdadeira Economia Política, isto é, com aquela política à qual cada nação individual tem que obedecer a fim de progredir em suas condições econômicas. Intitula sua obra A Natureza e as Causas da Riqueza das Nações, isto é, de todas as nações da huma- nidade inteira. Fala dos vários sistemas de 
Economia Política em uma parte específica de sua obra, apenas para demonstrar sua ineficácia e para provar que a Economia 'Política' ou nacional deve ser substituída pela 'economia cosmopolita ou mundial (LIST, 1983, p. 89).

Desta forma, List chega à conclusão que está implícita na teoria smithiana a ideia de um estado de paz perpétua, que serve como fundamento para todos seus argumentos. Qualquer coisa que o Estado faça para regular a atividade econômica na promoção da prosperidade pública são atitudes desnecessárias e nocivas aos indivíduos.

Para List, o grande problema em se partir de uma base cosmopolítica é esquecer que o mundo é dividido por diferentes nacionalidades, que têm bases de poder e interesses completamente diferentes umas das outras. Na busca por alcançá-los, as diferentes nações acabam se opondo entre si, e, todo autor

\section{[...] ao dar à sua economia cosmopolítica a denominação de política, dispensa essa ex- plicação, efetuando, por uma transposição de termos, também uma transposição de sentido, e dessa forma ocultando uma série de graves erros teóricos (LIST, 1983, p. 90).}

Para o autor, todos os teóricos econômicos a partir de Adam Smith vão seguir e repetir as ideias de Quesnay e da escola fisiocrática. Que o bem-estar do indivíduo só será atingido quando for alcançado o bem-estar de toda a humanidade.

Após a exposição de sua crítica à teoria liberal, List propõe a distinção entre estes dois métodos:

Distinguir a economia dos indivíduos da economia das sociedades, e diferenciar, quanto a esta última, entre a verdadeira Economia Política ou nacional (a qual, emanando do conceito e da natureza da nação, ensina de que maneira determinada nação, na atual situação do mundo e nas suas próprias relações nacionais específicas, pode manter e melhorar suas condições econômicas) e a economia cosmopolítica, que se origina da suposição de que todas as nações da terra formam uma única sociedade que vive em perpétuo estado de paz (LIST, 1983, p. 91).

Ao abstrair a realidade, aceitando uma união ou uma confederação universal de todas as nações, criando assim um estado de paz perpétuo, o princípio do livre comércio internacional passa a ser totalmente justificável. Os benefícios que este trouxe aos diferentes estados que fazem parte dos Estados Unidos da América, às diversas províncias da França e aos vários estados germânicos aliados foram muitos, e pode-se deduzir o tremendo benefício que este traria ao mundo.

Outro ponto de defesa dos benefícios do livre comércio é a migração pelas nações mais civilizadas de sua força de produção a países menos desenvolvidos. Com o passar dos anos e o desenvolvimento destas nações, o capital material atinge uma dimensão tal que necessariamente transborda para países menos civilizados. Desta forma, a visão liberal está coberta de bons argumentos na defesa de seu ponto de vista.

Porém, para List todo princípio que queira ser reconhecido e aplicado pela ciência, e mais, queira iluminar a prática econômica, deve ser um princípio real que a prática não pode ignorar. O grande problema da escola liberal é que esta não leva em conta as especificidades do mundo real, a natureza das nacionalidades, seus interesses e realidades distintas, e ainda tenta conciliar isto com a ideia de união universal e paz perpétua entre elas.

Para o autor, a escola liberal confunde os efeitos com as causas: 
Entre as províncias e os Estados que já estão politicamente unidos entre si, existe um estado de paz perpétua; dessa união política origina-se sua união comercial, sendo, em consequência dessa paz perpétua assim mantida, que a união comercial se tornou tão benéfica a elas. Todos os exemplos que a História é capaz de mostrar comprovam que a união política abriu caminho, e a união comercial veio depois (LIST, 1983, p. 93).

Partindo disto, List chega a uma das grandes conclusões de sua obra, algo que ele chama de uma conclusão irrefutável:

\section{[...] nos dias atuais, o resultado geral do co- mércio não seria uma república universal, mas, pelo contrário, uma sujeição total das nações menos adiantadas à supremacia da potência industrial, comercial e naval atualmente dominante (LIST, 1983, p. 93).}

A única maneira de haver uma república universal, em que todas renunciassem seus interesses egoístas, é quando estas atingirem o mesmo grau de desenvolvimento industrial, cultural e de poder. É somente a partir deste ponto que se poderá desenvolver o livre comércio. Mas como alcançar este estágio? Para List (1986), o sistema protecionista é a única maneira de colocar uma nação mais atrasada em pé de igualdade com a nação dominante e, desta maneira, é o meio mais eficaz para se alcançar a união final das nações e promover a verdadeira liberdade de comércio.

Dado isto, a Economia Nacional é a ciência que, partindo corretamente dos interesses e do estágio de desenvolvimento de uma determinada nação, nos mostra como cada uma delas pode alcançar um estado de desenvolvimento tal para comercializar com as demais de maneira liberal.

\section{6_John Maynard Keynes e \\ a Economia da Paz ou da Guerra}

John Maynard Keynes, economista britânico, nasceu em 5 de junho de 1883 em Cambridge, e faleceu em 21 de abril de 1946, próximo ao condado de East Sussex. Filho da alta classe média e da elite intelectual inglesa, sua influência familiar foi um forte estímulo ao envolvimento com assuntos públicos, particularmente em questões de comércio e finanças.

Nessa medida, Keynes passou dois anos no India Office ${ }^{5}$ entre 1906 e 1908, voltando para Cambridge, como professor em Economia, onde lecionou até 1915, embora tenha feito parte do King's College até o fim de sua vida. Keynes também se tornou editor do Economic Journal entre 1911 e 1945, período que lhe despertou o interesse por temas os quais o acampariam a vida inteira.

Em 1915, foi para o Tesouro inglês e sua carreira como funcionário público culminaria na Conferência de Paz de Paris, em 1919, da qual participaria como principal representante do Tesouro na delegação britânica. Inconformado com o tratamento dispensado pelos vitoriosos da I Guerra Mundial afastou-se da delegação antes que o Tratado de Versalhes fosse assinado. As Consequências Econômicas da Paz, publicado em 1919, foi escrito imediatamente após seu retorno de Paris, como reação indignada à postura dos Aliados perante a Alemanha.

O sucesso da publicação dessa obra marcou um ponto de inflexão na carreira de Keynes, que o afastaria formalmente do centro decisório da política econômica britânica até 1940, embora tenha colaborado com o governo, porém sustentando posição independente. $\mathrm{O}$ episódio marcaria o primeiro, de muitos outros, em que Keynes persistiu na difusão de suas ideias e viu frustradas suas tentativas de influenciar as políticas públicas.

Keynes foi muito ativo na tentativa de reconstruir um "novo liberalismo", inclusive ao participar do comando do 
The Nation and Atheneum ${ }^{6}$ publicação semanal que pretendia influenciar a posição do Partido Liberal britânico.

Já no final da década de 1920, passou a se envolver em debates relacionados ao impacto de obras públicas sobre o desemprego, que se estenderam pela década de 1930, quando produziu obras maiores, tais como "Treatise on Money", em 1930, e, em 1936, o revolucionário A Teoria Geral do Emprego, do Juro e da Moeda, com influência mais intensa e mais duradoura do que o bestseller As Consequências Econômicas da Paz.

Keynes pode ser considerado o responsável pelo retorno ao que afinal se conhecia como "economia política". $\mathrm{O}$ estudo do pensamento econômico keynesiano, principalmente em As Consequências Econômicas da Paz se faz fundamental ao atual debate em Economia Política Internacional, se transformando em um exemplo de análise, no qual o autor elucida a importância das relações políticas entre as nações, bem como o contexto histórico na qual estão inseridas e como esse conjunto de fatores influencia a formação de políticas econômicas em nível global. Obra que nasceu da convicção profunda de que o Tratado de Versalhes levaria ao desastre, reflete em suas diversas faces uma época de mudanças radicais, dentro e fora do campo teórico, na realidade econômica e política global. Neste sentido, pode-se considerar que a obra contém diversos livros:

\section{[...] é ao mesmo tempo um panfleto político que ataca a moralidade do tratado quando compa- rado às condições que regularam o armistício, uma discussão técnica das suas cláusulas eco- nômicas, uma discussão nostálgica das relações entre nações e classes antes de 1914 e um conjunto de propostas para enfrentar problemas europeus na segunda metade de 1919 (MOGGRIDGE, 1992, p. 324.}

Conforme anotação anterior, a análise e a compreensão da teoria desenvolvida por Keynes não devem ser destacadas do contexto histórico, no qual o autor estava inserido. Em As Consequências, após uma breve introdução, Keynes caracteriza os problemas estruturais das economias europeias naquele período. Em um primeiro momento, pode-se classificar o continente europeu antes e depois de 1870.

Nos anos anteriores à década de 1870, diferentes partes do continente haviam se especializado na produção de alguns produtos, mas tomada em conjunto a Europa era substancialmente autossuficiente. Após 1870, desenvolveu-se em larga escala uma situação sem precedentes, e nos cinquenta anos seguintes a condição econômica da Europa tornou-se peculiar e instável: excesso de população, a economia alemã como uma potência central, instabilidade psicológica das classes operária e capitalista (uma versão keynesiana da luta de classes) e instabilidade da oferta de alimentos originários do Novo Mundo. No entanto, em nenhum momento Keynes se refere à resposta protecionista europeia à ameaça competitiva dos grãos "extra europeus" que se seguiu após 1870 . Ao caracterizar as economias europeias, Keynes destaca o conjunto de fatores, dos quais dependia o equilíbrio de cada economia e do continente como um todo:

\section{O hábito de acumulação dos europeus, antes da guerra, era a condição necessária mais importante entre os fatores externos que mantinham o equilíbrio da Europa (KEYNES, 2002, p. 14).}

Ao descrever a polarização econômica protagonizada pelo Velho Mundo de um lado e o Novo Mundo do outro, começa a ficar clara sua tentativa de compreender as implicações econômicas das relações e estruturas políticas no período. No entanto, mesmo antes da guerra o equilíbrio es- 
tabelecido entre as antigas nações e os novos recursos já estava ameaçado. Segundo o autor, a prosperidade da Europa tinha como base o fato de que, a partir do amplo excedente exportável de alimentos na América, era possível adquirir esses alimentos a um preço modesto. Mas este cenário já não era mais tão seguro ou garantido, dado o crescimento da população no Novo Mundo, em especial nos Estados Unidos.

Em 1914, a demanda interna de trigo nos Estados Unidos se aproximava da produção do país, e não estaria longe o momento em que só em anos de colheita excepcional haveria um excedente exportável para o continente europeu. A clara dependência dos países do Velho Mundo em relação ao suprimento de alimentos não era apenas uma questão de escassez, mas uma nova ordem internacional que começava a dar indícios de sua imposição, conforme Keynes destaca:

\footnotetext{
Naquela época manifestava-se uma tendência à escassez, sob a forma não tanto de inexistência de fartura como de um aumento regular do custo real. Em outras palavras, tomando o mundo como um conjunto, não havia propriamente falta de trigo, mas era necessário pagar mais para conseguir uma oferta adequada.

[...] Em suma, a reivindicação da Europa com respeito aos recursos do Novo Mundo se tornava precária; a lei dos retornos decrescentes finalmente se reafirmava, tornando necessário que a Europa a cada ano fornecesse uma quantidade maior de outros produtos em troca da mesma quantidade de pão; assim, os europeus não se podiam permitir a desmobilização de qualquer uma das suas principais fontes supridoras (KEYNES, 2002, p. 15-16).
}

É neste cenário que irrompe a I Guerra Mundial, prejudicando esse sistema já fragilizado e colocando em perigo toda a Europa. A população do continente excedia em grande medida a oferta dos meios de sobrevivência, sua organização foi destruída, o sistema de transporte desarticulado e a produção de alimentos fortemente prejudicada.

Com o fim da guerra foi atribuído à Conferência de Paz de Paris, iniciada em 18 de janeiro de 1919, o restabelecimento das condições de vida na Europa. Entretanto, o ponto central da Conferência não se concentrou nas preocupações com o futuro do continente, mas nas condições que seriam estabelecidas aos países derrotados na guerra.

Keynes em As Consequências analisou com certo grau de detalhamento as provisões econômicas e financeiras do tratado de paz com a Alemanha. Entretanto, a grande contribuição de sua obra para o estudo em EPI está no terceiro Capítulo, quando o autor descreve o processo decisório do Tratado, bem como seus principais atores. Antes de avaliar os aspectos técnicos dos termos estabelecidos, o autor buscou examinar alguns dos fatores que influenciaram sua preparação, para então compreender a verdadeira origem de muitos desses termos.

Keynes evidencia como os interesses franceses, representados por Clemenceau, prevaleceram na medida em que os principais traços econômicos do Tratado eram idealizados. $\mathrm{O}$ autor deixa bastante claro qual a ideia presente no tratamento dado à Alemanha quando se refere ao Primeiro Ministro da França da seguinte maneira:

\footnotetext{
Portanto, sua filosofia das relações internacionais não guardava espaço para qualquer sentimentalismo. As nações são coisas reais; uma delas é objeto do nosso amor, as demais merecem nossa indiferença - ou ódio (KEYNES, 2002, p. 20).
} 
Dessa forma, Keynes conclui que:

A glória da nação amada é um objetivo desejável, que precisa ser alcançado geralmente à custa dos seus vizinhos. A política de poder é inevitável e nada há de muito novo a aprender sobre esta guerra, ou os objetivos pelos quais ocorreu. A Inglaterra tinha destruído um rival no comércio, como em casa no século precedente; e um capítulo importante se encerrara no conflito secular entre a glória da Alemanha e a da França (KEYNES, 2002, p. 20).

Contudo, essa é apenas uma generalização das reais causas que justificavam a paz que Clemenceau considerava necessária para o poder e segurança da França. Para examinar tais detalhes, Keynes analisa as causas históricas atuantes nas relações entre a França e a Alemanha. Antes da Guerra Franco-Germânica, a população francesa se aproximava da alemã, mas a indústria do carvão e do ferro e a navegação marítima alemã estavam em seus primeiros estágios, enquanto a riqueza da França era muito superior. Após a perda da Alsácia-Lorena, os recursos dos países já não eram muito diferentes. Mas, anos depois, este cenário se alterou completamente.

Em 1914, a população da Alemanha era aproximadamente $70 \%$ superior a da França e o país havia se tornado um dos mais importantes do mundo em termos de indústria e comércio internacional. Por outro lado, a França tinha uma população estagnada e, relativamente, havia decaído em riqueza e capacidade de produzi-la. Portanto, o futuro da França parecia o mais precário entre os países vitoriosos da I Guerra Mundial.

Conforme relatado por Keynes, havia uma visão de que a guerra civil na Europa seria uma situação recorrente, onde os conflitos entre grandes potências que se desenrolaram naqueles últimos cem anos voltariam a ocorrer. Segundo o autor, a política francesa representada por Clemenceau tinha como base a crença de que essencialmente a antiga ordem não mudaria o futuro do continente, pois uma paz "magnânima e justa" baseada em um ideal como proposto pelo presidente norte americano só retardaria a recuperação alemã.

Assim, nasceu sob o pretexto da Conferência de Paz a necessidade de obter garantias contra a ameaça a qual a Alemanha representava. Mas qualquer garantia poderia aumentar o ressentimento alemão e, portanto, a probabilidade de uma subsequente revanche tornava necessárias outras medidas para esmagá-la.

Em suma, o tratado de paz estabelecido pela Conferência, em termos práticos, atrasava e desfazia o progresso que a Alemanha havia alcançado desde 1870 . Na medida do possível, a política da França impunha perdas territoriais que, entre outras determinações, implicavam uma redução da população alemã e a destruição do seu sistema econômico. Sendo assim, a mordacidade da crítica de Keynes reflete claramente sua frustração quanto às decisões finais do Tratado de Versalhes e sua oposição em relação ao tratamento reservado à Alemanha.

Em As Consequências Econômicas da Paz, Keynes procurou justificar as razões de sua objeção tanto ao Tratado quanto a toda política da Conferência no tocante aos problemas econômicos da Europa. Para o autor, os representantes dos países vitoriosos da I Guerra Mundial cometeram um grande erro ao se concentrarem nos temas políticos e na busca de uma segurança utópica, sem considerar a unidade econômica do continente. Neste sentido, a avaliação da influência do contexto histórico e de seus atores políticos se torna fundamental para a compreensão dos termos estabelecidos no Tratado de Versalhes. 
Diante disso, cabe realçar que não cabe ao presente artigo uma descrição detalhada ou qualquer tipo de avaliação técnica dos termos elaborados, mas a ênfase à tentativa do autor em compreender as implicações econômicas das relações políticas mundiais, nas quais o contexto da Conferência estava inserido no período pós-guerra.

O ponto central da crítica de Keynes à Conferência de Paz de Paris está no fato de que o futuro da Europa como um todo não constituía uma real preocupação, mas expressava a iminente ameaça que a Alemanha representava para o suposto equilíbrio do continente, como o próprio autor descreve:

As preocupações da Conferência, boas e más, se relacionavam com fronteiras e nacionali-

dades, com o equilíbrio de poder, a expansão imperialista, o futuro enfraquecimento de um inimigo forte e perigoso, com a vingança e a transferência pelos vitoriosos de uma carga financeira insuportável para os ombros dos vencidos (KEYNES, 2002, p. 36).

A economia da Alemanha no período anterior à guerra estava fundamentada em basicamente três pilares: um setor exportador representado por seu comércio ultramarino, um setor industrial pautado na exploração de ferro e carvão e um sistema de transporte articulado. De maneira geral, os termos do tratado miravam a destruição da base do sistema econômico do país, mas principalmente os dois primeiros fatores foram afetados significativamente.

Sob a ótica apresentada por Keynes, o tratado de forma alguma estava orientado para a reabilitação econômica da Europa, dado que não havia nenhuma disposição direcionada ao restabelecimento das finanças desordenadas de países como França e Itália, nada que transformasse as potências centrais derrotadas em "bons vizinhos", nem mesmo alguma forma de pacto de solidariedade econômica entre os próprios aliados. Pelo contrário, o que prevaleceu no resultado da Conferência foram os interesses individuais de cada nação vitoriosa, defendidos ali por seus respectivos representantes. Portanto, o tratado de paz refletia diversos pontos de vista acerca do futuro da Europa, exceto a preocupação com o futuro econômico das nações cujos destinos foram de certa forma manipulados e subjugados.

Segundo Keynes, o perigo enfrentado pela Europa era a rápida queda do padrão de vida, na qual poderia destruir o que restava da organização social e era esse perigo que o tratado de paz deveria combater.

Embora As Consequências seja uma referência maior para estudo em Economia Política Internacional, fazem-se necessárias algumas breves considerações sobre as sugestões presentes na Teoria Geral do Emprego, do Juro e da Moeda que expressam o pensamento keynesiano e sua importância para uma EPI.

Keynes não definiu um programa de política pública na Teoria Geral, mas apresentou, na prática, como a política de redução das taxas de juros de longo prazo e a reforma do sistema monetário internacional eram medidas estruturais necessárias para encorajar o investimento e o consumo do setor privado, principalmente em um cenário pós-guerra no qual a Europa se encontrava.

A crítica do autor em suas notas finais se dirigiu desde aos mercantilistas que buscavam a vantagem nacional e a força relativa quanto às "ideias confusas dos contemporâneos" (como o próprio autor se refere) que defendiam um padrão-ouro internacional fixo e o laissez-faire no âmbito do crédito internacional e acreditavam serem justamente estas políticas as mais adequadas à manutenção da paz. O caráter nacionalista das políticas mercantilistas e suas tendências em promover a guerra evidencia a indiferença com que aceitavam os conflitos como uma consequência inevitável de um sistema monetário internacional. 
Em uma economia dependente fundamentalmente do balanço de pagamentos (como era o caso da Grã-Bretanha antes da guerra), as autoridades não dispunham de outros meios ortodoxos para combater as condições pós-guerra, a não ser por um excedente de exportação e uma importação de metal monetário à custa de seus vizinhos.

Assim, Keynes concluiu que, em tais circunstâncias, o método mais eficaz para um país obter alguma vantagem seria necessariamente à custa de seus vizinhos, ou seja, a prosperidade interna de uma nação dependeria diretamente do resultado de uma luta pela posse dos mercados e pela competição acirrada por metais preciosos.

\section{7_Considerações finais}

Tendo como objetivo estimular um primeiro debate sobre o estatuto da Economia Política Internacional e apontar eventuais caminhos para seu desenvolvimento, este artigo, partindo de uma breve reflexão sobre os problemas metodológicos enfrentados por esse novo campo de análise, buscou mostrar que a preocupação com uma interpretação da realidade internacional articulada entre a economia e a política já se manifestava de forma relativamente clara no pensamento de autores clássicos da ciência econômica.

Nessa medida, à guisa de síntese pode-se afirmar que Smith, ao colocar o problema da riqueza relacionada às relações entre as nações, suscitaria a defesa da primazia exclusivamente econômica na explicação dessas relações, perspectiva essa reiterada por Ricardo. Isto, por sua vez, incitaria uma resposta que viria por List no sentido de problematizar a questão, isto é, de politizar a origem da riqueza e, nessa mesma medida, as relações entre as nações. Já Keynes, vivendo uma situação concreta e com seu sentido pragmático viria a encaminhar o problema de modo a efetuar uma análise da excepcional situação internacional do Pós-Primeira
Grande Guerra perfeitamente articulada em torno da economia e da política em vigor.

Naturalmente, dado o espaço e o escopo do trabalho, a questão não se esgota aqui. O que se pretende lograr com estas considerações é que os estudiosos dos problemas internacionais, particularmente da economia, se vejam motivados e apoiados para oferecer caminhos para a construção de uma Economia Política Internacional enquanto campo autônomo de conhecimento, o que se reveste de fundamental importância no mundo atual.

\section{Notas}

${ }^{1}$ A tradução literal de Volsfreund aus Schwaben é "Amigo do povo da Suábia", o que demonstra explicitamente o caráter protecionista do pensamento de List.

${ }^{2}$ União aduaneira criada por iniciativa da Prússia em 1834, com o objetivo de implantar uma zona de livre-comércio entre os Estados membros, favorecendo a união política alemã em 1871.

${ }^{3}$ Nome abreviado do Report on the Subject of Manufactures, apresentado ao Congresso Americano em 5 de dezembro de 1791 pelo então secretário do Tesouro americano Alexander Hamilton, que recomendava políticas econômicas para estimular a economia da nova república e assegurar a independência americana.

\author{
${ }^{4}$ Série de 12 cartas em que List \\ busca esclarecer aos leitores seu \\ ponto de vista sobre a teoria \\ econômica. \\ ${ }^{5} \mathrm{O}$ India Office era um \\ departamento do governo \\ britânico, criado em 1858, para \\ supervisionar a administração \\ das províncias da colônia inglesa. \\ ${ }^{6}$ Em 1931, seria fundido com o \\ New Statesman, transformando- \\ se no New Statesman and Nation, \\ retratando a convergência entre \\ liberais e trabalhistas no quadro \\ da Grande Depressão. \\ ${ }^{7}$ Pode-se atribuir ao conflito \\ secular entre a glória da \\ Alemanha e a da França, \\ mencionado pelo autor, a Guerra \\ Franco-Germânica no final do \\ século XIX.
}




\section{Referências bibliográficas}

DENIS, H. História do Pensamento

Económico. Lisboa: Livros

Horizonte, 2000.

FUSFELD, D. R. A era do economista. São Paulo: Saraiva, 2001.

GILPIN, Robert. A Economia Politica das Relações Internacionais. Brasília: Editora Universidade de Brasília, 2002.

GILPIN, Robert. Global Political Economy: understanting the international economic order. New Jersey: Princeton University Press, 2001.

GONÇALVES, R. Economia Política Internacional. Rio de Janeiro:

Campus, 2005.

HUME, David. Da origem e progresso das artes e ciências. Hume: vida e obra. São Paulo: Nova Cultural, 1999.

KEOHANE, Robert O; NYE, Joseph S. Power and Interdependence. 2nd edition, Cambridge, Mass: Harper Collins Publishers, 1989.

KEYNES, John M. As consequências econômicas da paz. São Paulo: Imprensa Oficial do Estado de São Paulo; Editora Universidade de Brasília, 2002.

KEYNES, John M. Teoria Geral do Emprego, do Juro e da Moeda. $2^{\mathrm{a}}$. ed. Rio de Janeiro: Editora Fundo de Cultura, 1970.
KINDLEBERGER, Charles P. Power and money. The Economics of International Politics and the Politics of International Economics. New York/London: Basic Books Inc. Publishers, 1970.

LIST, Georg. Sistema Nacional de Economia Política. São Paulo: Abril Cultural, 1983 (Os Economistas).

LOCKE, John. Ensaio acerca do entendimento humano. São Paulo: Abril Cultural, 1978

(Os Pensadores).

MOGGRIDGE, Donald Edward. Maynard Keynes: an economist's biography. London/New York: Routledge, 1992.

MORGENTHAU, Hans J. A política entre as nações. Brasília: Editora

Universidade de Brasília; Imprensa Oficial do Estado de São Paulo; Instituto de Pesquisa de Relações Internacionais, 2003.

NAPOLEONI, C. Smith, Ricardo, Marx. Rio de Janeiro: Edições Graal, 1991.

NYE, Joseph. Understanding International Conflicts: an introduction to theory and history. New York: Longman, 1997.
RACY, J. C.; KABARDZINSKY, J. S.; LAUNAY, M. M. Breve introdução à Teoria de Relações Internacionais para estudantes da Economia Política Internacional. $3^{a}$. Semana Nacional da Ciência e Tecnologia da Universidade Presbiteriana Mackenzie, v. 1, n. 1, 2011, São Paulo.

RICARDO, David. Princípios de Economia Política e Tributação. São Paulo: Nova Cultura, 1996.

SMITH, Adam. Investigação sobre a riqueza das nações. São Paulo: Nova Cultural, 1996.

SMITH, Adam. Investigação sobre a natureza e as causas da riqueza das nações. São Paulo: Abril Cultural, 1978 (Os Pensadores).

STRANGE, Susan. Paths to International Political Economy. New York: Routledge, 1984.

STRANGE, Susan. States, firms and diplomacy. In: FRIEDEN, JEFFRY A.; LAKE, DAVID, A., 3th. edition. International Political Economy: perspectives on global power and wealth. New York: St. Martin's Press, pp. 183-199, 1997.
E-mail de contato dos autores:

racjo@uol.com.br

alvarojr2003@uol.com.br

bfalsarella@gmail.com

Laura.goncalves@fiesp.org.br

Artigo recebido em agostoo de 2011 aprovado em setembro de 2012 
